\title{
INVESTIGACIÓN/RESEARCH
}

\section{LA MUJER EN LA POLÍTICA: ¿IGUALDAD O DIFERENCIA? UNA INVITACIÓN A LA REFLEXIÓN}

Natalia Soledad D'Elia': Universidad Nacional de La Plata, Argentina.

nataliasoledaddelia@yahoo.com.ar

\section{RESUMEN}

Este trabajo expone distintas posiciones que hicieron a la lucha por la vindicación y reivindicación de los derechos de la mujer en la sociedad occidental. Una postura que coincide en reclamar la igualdad y respetar la diferencia entre los géneros. Si bien parece una ambigüedad, se pone el énfasis en lo que sucede con las mujeres políticas de nuestro tiempo, desde el punto de vista discursivo, para entender que son categorías necesarias para lograr una sociedad más justa e igualitaria.

PALABRAS CLAVE: Mujer - Género - Política - Discurso - Igualdad - Diferencia.

\footnotetext{
${ }^{1}$ Natalia Soledad D'Elia: Doctoranda en Comunicación Social por la Facultad de Periodismo y Comunicación Social de la Universidad Nacional de La Plata, Argentina.

Correo: nataliasoledaddelia@yahoo.com.ar
} 


\title{
WOMEN AND POLITICAL PARTICIPATION: EQUALITY OR DIFFERENCE? AN INVITATION FOR REFLECTION
}

\begin{abstract}
This paper exposes varied positions that emerged in the discussion on the struggle for the vindication and the achievement of women's rights in western society. A view that agrees in claiming equal treatment and respecting gender parity. Even though it seems an ambiguity, the emphasis is on what happens to female politicians of our time, discursively speaking, to find that they are necessary categories for a fair and equal society.
\end{abstract}

KEY WORDS: Women - Gender - Politics - Discourse - Equality - Difference.

\section{INTRODUCCIÓN}

Hace tiempo ya, me pregunto por la cuestión de la mujer en el ámbito político. Y pienso: si lo personal es político (Millett, 1975), es decir que la relación entre varones y mujeres en el ámbito privado es una cuestión política en la que, aún hoy, hay jerarquías, ¿qué pasa en el ámbito de la política?

En este trabajo, intento exponer distintas posiciones que hicieron a la lucha por la vindicación y reivindicación de los derechos de la mujer en la sociedad occidental. No me adentraré aquí en las problemáticas existentes en otras culturas, porque mi honestidad obliga a explicar mis ideas desde este punto de mira. Por lo tanto, me declaro mujer occidental que coincide en reclamar igualdad y respetar la diferencia en todos los ámbitos.

Y si bien suena ambiguo reclamar ambos derechos, en las próximas líneas fundamentaré mi postura enfatizando en lo que sucede con las mujeres políticas de nuestro tiempo. Aquellas mujeres que nos representan en el poder y que toman decisiones en las cuestiones de Estado.

Para empezar, es preciso aclarar que mi reflexión parte de lo que se produce a nivel discursivo porque decimos lo que pensamos y hacemos lo que decimos. Así que, ello, me lleva a formular la siguiente pregunta: ¿Si hay paridad entre, las mujeres y los varones, en los puestos de poder de un Estado, significa que se ha alcanzado la igualdad por la que tanto se ha reclamado?

\section{METODOLOGÍA}

En el presente artículo se trabaja la problemática de género en ámbito político sustentado en un exhaustivo análisis de fuentes que permite describir el estado actual del mismo. Es así que se propone discutir las categorías de paridad, igualdad y 
diferencia para arribar a las conclusiones que implican una coexistencia necesaria de las tres en el proceso de construcción de una sociedad más justa.

En este sentido, es preciso comenzar con una genealogía teórica que explique los orígenes de las luchas por lograr mayor participación femenina en las cuestiones ciudadanas, puntualizando nuestro interés en el caso argentino.

\section{ANÁLISIS Y DISCUSIÓN \\ 3.1 Una breve genealogía del Feminismo}

Es imprescindible comenzar haciendo una genealogía, aunque sea breve, de las etapas por las que ha atravesado el Feminismo y las posturas que se han tomado ante la cuestión de la mujer y el poder, para entender el presupuesto que formulé anteriormente, sobre la igualdad.

El Feminismo tiene su origen en la lucha por desterrar el patriarcado que se ha enraizado desde hace muchos años en nuestra cultura.

El patriarcado es un orden social definido por relaciones de poder entre los sexos cuyo origen, según datos de registros arqueológicos, se puede situar en el año $2.400 \mathrm{aC}$. (Hernando, 2008). Como su nombre lo indica, el poder, en el sistema patriarcal, lo ejerce el padre, el varón. Y según la visión marxista, estas relaciones tienen una base material que estructura relaciones sociales jerárquicas y en las que hay una solidaridad entre los hombres que les permite dominar a las mujeres. Según Hartmann (1979, p. 15), la base material de este orden social "es el control del hombre sobre la fuerza de trabajo de la mujer. Este control se mantiene, negando a la mujer el acceso a los recursos productivos económicamente necesarios y restringiendo la sexualidad de la mujer".

Lo cierto es que este orden social, atravesó todas las aristas de nuestra cultura y estructuró la vida de las personas, invisibilizando a la mujer, mostrándola como objeto, incapaz de pensarse a sí misma, sometiéndola a normas institucionalizadas políticamente para que reprodujese el patriarcado y perdure por años.

Por lo que mencioné anteriormente, la invisibilización de la mujer no comienza con el pedido de reivindicación derechos que las feministas de los años '60 y '70. Sino que las mujeres vienen reclamando desde mucho antes. Lo que sucede es que la historia fue escrita por varones, por lo tanto no ha sido sujeto de ella, no se la ha nombrado y por ende, permaneció invisible porque no tenía un lugar en el espacio público. Es que a las mujeres no se les permitía gozar de un espacio propio, es decir, tener una voz propia. Las mujeres crecieron en silencio. No todas tenían acceso a la lecto escritura o a una educación superior, generalmente, las mujeres alfabetas pertenecían a familias de la alta sociedad, que acostumbraban a entregarlas en matrimonio por conveniencia económica o estatus social. En tal sentido, la mujer siempre apareció vinculada en relación a un varón. Este sistema se llamará "parentesco", una forma de patriarcado que Levi Strauss define como una imposición de organización cultural sobre los hechos de la procreación biológica (Rubin, 1996). Lo que implica una organización que 
establece posiciones y jerarquías dentro de la unidad familiar en la cual el hombre ejerce el dominio absoluto.

Las mujeres pensaban y escribían en silencio, pero su obra no podía ser mostrada porque era cuestión de varones. La ciencia, la política, el trabajo, y todas aquellas actividades que intervenían en la vida pública, fueron tomadas como propias de los hombres, durante mucho tiempo.

Pero fueron las mujeres quienes comenzaron a visibilizar aquella exclusión que no les permitía ser libres. Así, nace el Feminismo.

Femenías (2012: p. 4-11) cita a Celia Amorós (1997) quien propone sintéticamente, tres etapas del feminismo:

- Protofeminismo: Esta etapa se caracteriza por exigir para las mujeres los mismos derechos que gozan los varones de su mismo nivel social, pero sin cuestionar las diferencias existentes, en este sentido, entre los estratos sociales. Aquí se concibe a la mujer por su naturaleza: hay un dato biológico que determina el "ser mujer". Se remonta aproximadamente al año 1400, con obras de algunas escritoras como Christine de Pizán ${ }^{2}$.

- Feminismo: nace con la Ilustración y los conceptos que desafían el modelo de la sociedad jerárquica anclada en la naturaleza, aportando dos conceptos: igualdad y universalidad, que permiten legitimar los derechos de todos -varones y mujeresindependientemente de su estrato social. Pero más adelante, se empezó a cuestionar el "universal" porque la Revolución de 1789 no le reconoció a las mujeres sus legítimos derechos como ciudadanas. Simone de Beauvoir (1949: p...) se pregunta: "¿qué es ser mujer?", y responde: "La mujer no nace, deviene", lo que indica que ese devenir acontece socialmente producto de la relación de poder existente entre el varón y la mujer, en la que el dominio es ejercido por el primero. A raíz de ello, en Estados Unidos se acuñó la palabra género, que pasó a designar lo culturalmente construido sobre la diferencia sexual. Por lo tanto el sexo es el dato biológico y el género es el sexo socio-culturalmente construido.

- Postfeminismo: en esta etapa se considera que los géneros operan como construcciones culturales, que pueden modificarse o construirse por la acción sociocultural de los géneros que el imaginario social sostiene. Influyeron las posturas revisionistas de los presupuestos de la modernidad y el postestructuralismo, la relectura del psicoanálisis freudiano y la crítica de la heterosexualidad compulsiva. Estas posturas proclamaron la fractura del universal, el enaltecimiento de la noción de diferencia y la desaparición del sujeto representado siempre por el sujeto masculino. Se resignificó la noción de poder y fue pensado más allá de los aparatos ideológicos del Estado. El método se desplazó hacia la deconstrucción. Aquí podemos situar a la Teoría Queer y su mayor exponente, Judith Butler (1982), citada por Femenías (2012: p. 7), quien define el género como "un estilo de vivir el propio cuerpo en el mundo", como un modo de posicionarse ante las normas culturales. Ella desplaza esta definición hasta considerar al sexo-género como producto performativo y paródico.

\footnotetext{
${ }^{2}$ Christine de Pizán escribió La ciudad de las damas en el año 1405.
} 
Estamos en este punto, en la consideración de la diferencia. ¿Eso significa que el reclamo de la igualdad caducó? La lucha que las mujeres emprendieron por conseguir los mismos derechos ciudadanos que los varones, ¿ya no tiene sentido? En las próximas líneas trataré de exponer mi postura, mis ganas de que la igualdad siga siendo una meta a alcanzar porque no estoy de acuerdo en que hay que ubicarse dentro de una de las etapas por sostener algunos de sus postulados. Prefiero pensar en que las convicciones se siguen, sin encasillamientos, para lograr un mundo mejor, más justo y más igualitario.

\subsection{Paridad, Igualdad, Diferencia}

Las categorías paridad, igualdad y diferencia, están estrechamente ligadas en los reclamos que vienen haciendo las mujeres. $Y$ me parece interesante mencionar las diferencias existentes entre las dos primeras, la oposición que existe con la tercera, para terminar afirmando mi presupuesto: las tres categorías constituyen un todo en la lucha por la igualdad planteada actualmente, en el ámbito de la política.

Propongo mirar un poco la historia de Argentina, donde a principios del Siglo XX, ya había grupos de mujeres que bregaban por conquistar espacios en la vida pública, o por lo menos, ser tenidas en cuenta como sujeto[a]s pensantes y capaces de aportar ideas para llevar a un país adelante. Dichos círculos estaban compuestos por mujeres de la alta sociedad que gozaban del acceso a una educación universitaria y a bienes materiales que eran inalcanzables para la mayoría femenina. El objetivo principal era defender los derechos de la mujer y luchar contra toda forma de discriminación y explotación. La discusión se conformaba por la oposición "Mujer = Madre / Mujer = Ciudadana". Y el sufragio empezó a ser un reclamo fuerte dentro de estos movimientos feministas (Bianchi y Sanchis, 1988).

Pero ya, instalada la discusión del sufragio femenino, que en principio se disponía para las mujeres "conscientes, alfabetas y mayores de edad", fue durante el Primer Período del Gobierno de Juan Domingo Perón (1946-1952) que la mujer consiguió ejercer su derecho al voto, ya que hasta entonces, la política era un espacio sólo de los varones. Eva Duarte sería quien llevaría adelante las políticas positivas hacia éste y otros temas que involucraban a las mujeres. Ella fue la figura intelectual, comprometida y popular, que tuvo una conexión única con el pueblo, en especial con las mujeres trabajadoras, lo que la convertirá luego en uno de los emblemas del Peronismo. Sin lugar a dudas, el logro del sufragio femenino en el año 1947 y la formación del Partido Peronista Femenino -que sumergía a las mujeres en las políticas de Estado de entonces- fue el puntapié inicial.

Lamentablemente, muchos intelectuales fueron perseguidos durante el Proceso Militar que se dio en Argentina entre el 24 de marzo de 1976 y el 10 de diciembre de 1983 . Y las mujeres no estuvieron exentas de ello.

Evidentemente, la recuperación de la democracia favoreció la participación de la mujer en el ámbito de la política. Y es a partir de ese momento, que las luchas ya no pasan sólo por encontrar lugares de participación donde se escuche la voz de la mujer, sino 
por conseguir espacios de toma de decisiones. En ese sentido, Filippini (2010) hace un trabajo cuantitativo en el cual explica la Ley 24.012 de 1991 llamada "Ley de Cupo Femenino" ${ }^{\prime 3}$ que obliga a los partidos políticos a reservar un $30 \%$ de los cargos o lugares en listas de candidaturas plurinominales para las mujeres, lo que permitiría un avance en pos de una democracia paritaria. Luego cita al Decreto 1246/00 que amplió la aplicación de la Ley de Cupo instituyendo la incorporación efectiva de candidatas mujeres, al fijar que las mismas debían ocupar un lugar en la lista que permitiera su elección si el partido obtenía los votos suficientes. La autora concluye que si bien, la Ley y el Decreto significaron un progreso en la lucha por la inclusión de las mujeres en las cuestiones de Estado, tanto a nivel nacional como provincial -vale decir en todas las provincias- la participación femenina es muy baja teniendo en cuenta que el número de afiliadas a los partidos políticos más grandes y tradicionales como el Justicialismo y el Radicalismo es alto. E incluso refiere que el hecho de que las mujeres sean elegidas para ocupar bancadas en el Poder Legislativo, no significa que presenten proyectos encarados desde la perspectiva de género, es más, la autora de la investigación aclara que son muy pocos y que generalmente se tratan de problemáticas que tradicionalmente se vinculan a las mujeres como la salud, minoridad y violencia. Y finalmente, indica que las mujeres en la política suelen ser meras acompañantes de proyectos producidos por los hombres y "apoyadoras" del pacto patriarcal que siempre excluyó la problemática de género.

La temática del cupo es interesante ya que permite delinear un debate: ¿el cupo femenino significa haber conseguido la paridad? ¿La paridad es lo mismo que igualdad entre los géneros? Desde mi punto de vista, no lo es porque la categoría paridad connota cantidad, por lo que La Ley de Cupos, tiene como objetivo que las mujeres igualen en número a los varones en el ejercicio de la política.

Ahora bien, se podría hacer un supuesto: en el caso de que existiese la paridad cuantitativa entre varones y mujeres en dicho ámbito, es decir, por ejemplo, que en un recinto legislativo hubiese un 50 por ciento de varones y otro 50 por ciento de mujeres, ¿estaríamos hablando de que se ha logrado la igualdad deseada?

¿Qué significa igualdad ciudadana entre varones y mujeres? Amorós la define perfectamente y dice:

El concepto de igualdad ¿de dónde surgió? Surgió, precisamente, cuando con la crisis de las jerarquías estamentales de la Revolución Francesa, fundamentalmente (...), con la crisis de las jerarquías estamentales, 'nobles', 'villanos', 'clérigos', se horizontalizaron los conceptos y aparecieron abstracciones universalizadoras como sujeto, individuo, ciudadano. Digamos que, en principio, se suponía que como tenían ese sentido universalizador, se le tenían que aplicar a todo el mundo, por lo tanto en la medida en que formamos parte del mundo, se le tenían que aplicar a las mujeres [...] La idea de ciudadanía es una abstracción polémica contra las jerarquías

\footnotetext{
${ }^{3}$ Véase Ley 24012 de 1991 y Decreto Reglamentario 379/93 Ley de cupo (No 24012) que publica la Comisión Económica para América Latina y el Caribe (CEPAL) en www.cepal.org/oig/doc/ArgentinaLey24012cupofemenino.pdf
} 
estamentales. Si decís que se debe hacer abstracción entre ser noble y villano a la hora de ser ciudadano, bueno, por qué no hacemos abstracción también a la hora de la jerarquía varón/ mujer, por la misma regla de tres se puede ser ciudadanos hora se sea varón, hora se sea mujer. Entonces, la idea de igualdad aparece con estas abstracciones y la idea de igualdad va unida a la posibilidad de articular vindicaciones. La igualdad no significa que las identidades de varones y mujeres sean idénticas, perdón por la redundancia. Significa que en determinados planos abstractos estamos en la misma situación. Pero ha hecho falta que aparecieran, históricamente, esas abstracciones y que no fueran entonces, aplicadas como términos restrictivos. Amorós $(2011)^{4}$.

Por lo tanto, hay que plantearse la igualdad en los planos abstractos de ciudadanía y participación política. Y esto tiene que ver no sólo con la cantidad de mujeres que accedan a los puestos de poder político, sino con la calidad en su participación. Lo que nos lleva directamente al plano discursivo.

¿Cuántas de las mujeres legislativas, por ejemplo, impulsan políticas positivas a favor de la mujer? O bien, ¿Cuántas de ellas emplean un discurso de carácter igualitario y cuántas retoman el discurso de los varones? Porque, coincido con Butler en que el discurso es performativo del género y que cuando se habla, se hace una parodia del mismo. Y aquí está el punto. Estos cuestionamientos indican que paridad no es lo mismo que igualdad. Son categorías diferentes. Mientras el primero se refiere a la cantidad, el segundo está ligado a la abstracción conceptual que implica la forma de hacer y decir la política.

Pero es necesario, en este estadio del planteo, incluir la categoría diferencia. Usualmente, se la usa y define como todo lo contrario a igualdad. Aunque preciso relacionarlas. El postfeminismo, postula el enaltecimiento de la diferencia pero no deja de lado a la igualdad. En el plano de la abstracción, que explica Amorós, tanto varones como mujeres no tienen la misma identidad, pero deberían ser considerados igualmente ciudadanos. Es decir, la realidad nos presenta un mundo con identidades diferenciadas, las que están siendo incluidas social y normalmente ${ }^{5}$ por los Estados democráticos, propiciando nuevos espacios de participación ciudadana y generando inclusión social. Ejemplo de ello es Argentina, cuya Presidencia es ejercida por una mujer que propone acciones positivas en pos de la igualdad ciudadana.

Ante este escenario, considero que la categoría diferencia está incluida dentro de la reivindicación de la igualdad, porque se trata de igualdad de derechos en el plano abstracto de ciudadanía. Porque todos y todas tenemos derecho al espacio público, a ejercer la política y a tomar decisiones importantes para lograr una sociedad más

\footnotetext{
${ }^{4}$ Conferencia impartida por Celia Amorós, el 11 de junio de 2011, con motivo de la celebración del 20 Aniversario del Curso de Teoría Feminista que ella dirigió en sus orígenes y que actualmente dirige la filósofa Ana de Miguel. Amorós repasa en su conferencia la historia del pensamiento feminista. Véase http://www.youtube.com/watch?v=v_xOnIGkTQ8\&feature=share

${ }^{5}$ Se hace referencia al sistema de normas culturales -y legislación existente en los Estados- que rigen la vida ciudadana.
} 
justa. No se trata de encasillarse y definirse como moderno/a o posmoderno/a, según se defienda tal o cual categoría.

En tanto los discursos sigan retomando el sistema patriarcal, que acecha desde hace tantos años y que no puede más que hacer sociedades retrógradas, presas de una ideología que anula la libertad del Ser, no se podrá llegar a la igualdad por la que tanto bregamos. Si todas y todos, reflexionamos sobre los derechos propios, utilizamos las herramientas políticas en pos de la igualdad social, generando inclusión, buscando alternativas, podremos lograr modelos nuevos de hacer política que otorguen oportunidades sociales, para finalmente, encontrar el camino que nos lleve a esa sociedad igualitaria soñada.

\section{CONCLUSIÓN}

Pensar en las categorías de paridad, igualdad y diferencia, significa reflexionar un poco sobre la historia del feminismo- que muchas veces las ha definido y reivindicado por separado- y entender que en este punto de la historia, en el comienzo del Siglo XXI, la realidad social nos presenta un escenario diverso en identidades, creencias, ideologías, formas de concebir el mundo y de vivir los cuerpos.

Si lo privado es político, el ámbito de la política mucho más aún... Los problemas de género, siguen existiendo gracias al sistema patriarcal que ha dominado durante siglos en la cultura occidental. Pero, de a poco, se van .visibilizando los logros del feminismo. Las mujeres participan más en política y ocupan cargos de máximo poder, como la Presidencia de una Nación.

Por eso, meditar sobre estas categorías nos hace recordar que debemos ser fieles a nuestras convicciones, que la paridad es necesaria en la cantidad y que la diferencia traerá nuevos aires ciudadanos que nos llevarán a la igualdad que queremos alcanzar. Que debemos desterrar por completo cualquier vestigio del patriarcado que ha llevado a una guerra sin sentido a mujeres y varones, dando como resultado una sociedad insegura, injusta, despiadada, opresora, racista, esclavista, discriminatoria, anuladora del Ser en plenitud. Que pensemos en nuevos discursos basados en lo que somos en verdad, íntegramente, interiormente sin importar lo que hasta ahora era "normal" o "moral". Porque esas normas y moral todavía conservan rasgos patriarcales que separan a la sociedad en excluidos y aceptados.

Propongo reflexionar sobre lo que pensamos y decimos, sobre lo que somos y lo que soñamos ser, hacer y vivir. Porque somos lo que hacemos... y hacemos lo que decimos... Mientras las mujeres y los varones sigan adoptando discursos patriarcales, la igualdad no será posible. El desafío será incluir las diferentes voces y aceptar que pueden tomar decisiones de Estado en pos de una sociedad democrática, igualitaria, para, luego, dar el paso a que los géneros se borren y la diversidad se incorpore al ámbito de la política, y de esa manera, abrir las puertas de una sociedad nueva, inclusiva e igualitaria. 


\section{BIBLIOGRAFÍA}

Amorós, C. (1997). Tiempo de feminismo. Sobre feminismo, proyecto ilustrado y posmodernidad, Catedra, Madrid.

Bianchi, S. y Sanchis, N. (1988). Mujeres y cambio social. En El Partido Peronista Femenino, CEAL, Bs. As.

Butler, J. (1982). Variations on Sex and Gender: Beauvoir, Witting and Foucault, Feminism as Cri. Tiq/Ut, University of Minnesota Press. Traducción Sánchez, A. (1990). En Teoría feminista y teoría crítica. Ensayos sobre la política de género en las sociedades de capitalismo tardío, Ediciones Alfons el Mighilnim, Valencia.

Femenías, M. L. (2012). El ideal del "saber sin supuestos" y los límites delco hacer filosófico. En Revista do Departamento de Filosofía da Pontifícia Universidade Católica de Minas Gerais, Brasil, pp. 1-13.

Filippini, Nilda, (2010). Los límites de la participación política de las mujeres en la Argentina. En Relaciones de género en la Patagonia, Actas de las $1^{0}$ Jornadas Patagónicas de Estudios de las Mujeres y Género, Edda Lía Crespo y Myriam Susana González, $1^{a}$ ed. Comodoro Rivadavia: Vela al Viento Ediciones Patagónicas, Argentina.

Hartmann, H. (1979). Un matrimonio mal avenido: hacia una unión más progresiva entre marxismo y feminismo. En Capital \& Class, 3, pp. 1-33.

Hernando, A. (2008). Género y Sexo. Mujeres, identidad y modernidad. En Claves de Razón Práctica, 188, diciembre, pp. 64-70.

Millett, K. (1975). Política Sexual, M. Aguilar Editor S. A., México.

Rubin, G. (1996). El tráfico de mujeres: Notas sobre la "economía política" del sexo. En Lamas Marta Compiladora. El género: la construcción cultural de la diferencia sexual, PUEG, México, pp. 35-96.

\section{WEBGRAFÍA}

Amorós, C. (2011). Conferencia 20 Aniversario del Curso de Teoría Feminista, España. http://www.youtube.com/watch?v=v_xOnIGkTQ8\&feature=share

Ley 24.012 de 1991 y Decreto Reglamentario 379/93, Argentina. www.cepal.org/oig/doc/ArgentinaLey24012cupofemenino.pdf

\section{Natalia Soledad D'Elia}

Licenciada y Doctoranda en Comunicación Social con Orientación en Periodismo por la Facultad de Periodismo y Comunicación Social de la Universidad Nacional de La Plata, Argentina. Dictó clases de Periodismo y Comunicación en el Colegio no 723 de la ciudad de Comodoro Rivadavia (provincia de Chubut, Argentina). Integrada al grupo 
de trabajo de la Unidad de Comunicación Institucional del Ministerio de Seguridad de la Provincia de Buenos Aires, Argentina. 